\title{
1 A taxonomic monograph of Ipomoea integrated across 2 phylogenetic scales
}

3 Pablo Muñoz-Rodríguez ${ }^{1 \dagger}$, Tom Carruthers ${ }^{1 \dagger}$, John R.I. Wood ${ }^{1,2}$, Bethany R.M. Williams ${ }^{1}$,

4 Kevin Weitemier ${ }^{3}$, Brent Kronmiller ${ }^{3}$, Zoë Goodwin ${ }^{4}$, Alex Sumadijaya ${ }^{1}$, Noelle L. Anglin ${ }^{5}$,

5 Denis Filer ${ }^{1}$, David Harris ${ }^{4}$, Mark D. Rausher ${ }^{6}$, Steven Kelly ${ }^{1}$, Aaron Liston ${ }^{7}$, Robert W.

6 Scotland $^{1 *}$.

$7{ }^{1}$ Department of Plant Sciences, University of Oxford. South Parks Road, Oxford OX1 3RB,

8 United Kingdom.

$9 \quad{ }^{2}$ Royal Botanic Gardens, Kew, Richmond, Surrey, TW9 3AB, United Kingdom.

$10{ }^{3}$ Department of Fisheries and Wildlife, Oregon State University, Corvallis, OR 97331, USA.

$11{ }^{4}$ Royal Botanic Garden Edinburgh, 20A Inverleith Row, Edinburgh EH3 5LR, Scotland,

12 United Kingdom.

$13 \quad{ }^{5}$ International Potato Center, Avenida La Molina 1895, La Molina, Lima, Peru.

$14{ }^{6} 53332$ French Family Science Center, 124 Science Drive, Duke University, Durham, NC

1527708, USA.

$16{ }^{6}$ Department of Botany and Plant Pathology, Oregon State University, Corvallis, OR 97331, 17 USA.

$18 \dagger$ These authors contributed equally to the work. 


\section{ABSTRACT}

22 Taxonomic monographs have the potential to make a unique contribution to

23 understanding global biodiversity. However, such studies, now rare, are often considered too

24 daunting to undertake within a realistic timeframe, especially as the world's collections have

25 doubled in size in recent times. Here, we report a global-scale monographic study of morning

26 glories (Ipomoea) that integrated DNA barcodes and high-throughput sequencing with the

27 morphological study of herbarium specimens. Our approach overhauled the taxonomy of this

28 megadiverse group, described 63 new species and uncovered significant increases in net

29 diversification rates comparable to the most iconic evolutionary radiations in the plant

30 kingdom. Finally, we show that more than 60 species of Ipomoea, including sweet potato,

31 independently evolved storage roots in pre-human times, indicating that the storage root is

32 not solely a product of human domestication but a trait that predisposed the species for

33 cultivation. This study demonstrates how the world's natural history collections can

34 contribute to global challenges in the Anthropocene.

\section{INTRODUCTION}

36 When Joseph Banks and Daniel Solander travelled with Captain Cook on the

37 Endeavour in 1768 , the plants they collected were new species to science ${ }^{1}$. Similarly, when

38 Robert Brown sailed to Australia in 1801, he too discovered and described a completely new

39 flora with many new species ${ }^{2}$. More than 200 years later, however, the task of deciding

40 whether a specimen represents a new species has become much more difficult because

41 taxonomists need to work through the large number of specimens held in natural history

42 collections, a number which has doubled since $1960^{3}$, and a massive accumulation of

43 literature. The provisional nature of species curation adds to these difficulties, reflecting the

44 fact that species-level taxonomy is incomplete and unsatisfactory for many taxa, especially

45 insects and tropical plants ${ }^{3}$. These difficulties come at a time when improved taxonomic 
46 knowledge is an urgent priority for policy makers ${ }^{4}$, environmental scientists ${ }^{5}$ and museum

47 directors $^{6}$ throughout the world. The Global Strategy for Plant Conservation, for example,

48 seeks to assess the conservation status of all plant species by 2020, but at present less than

$4925 \%$ of plant species have been assessed ${ }^{7}$, largely because of incomplete taxonomic

50 information ${ }^{8}$. Many suggestions have been made to enhance the accuracy, speed, accessibility

51 and relevance of taxonomy $y^{9,5,10-14}$; but, nevertheless, the pace of flowering plant taxonomy

52 has remained unchanged for the last 30 years $^{15}$. Finding ways to address these substantial

53 issues in a realistic timeframe is a recurring challenge ${ }^{4}$.

54 Much existing taxonomy is inaccurate because it is essentially country- or region-based

55 and inevitably depends on limited specimen sampling ${ }^{16}$. The choice of a particular

56 geographical area to document species is a pragmatic decision and reflects national priorities

57 and funding constraints as well as the interests of policy makers and taxonomists who are

58 focussed on the plants and animals of their region. However, species are often widely

59 distributed with the result that the same species may be described on multiple occasions from

60 different countries under different names (synonymy). Over time, issues of synonymy, when

61 combined with misidentification and poor species level sampling ${ }^{3,10}$ result in many tropical

62 plants being so poorly known that they are invisible to modern ecological and conservation

$63 \operatorname{tools}^{8}$. Furthermore, when existing taxonomy is so provisional, determining whether potential

64 new species are different from existing species is highly problematic with the consequence

65 that half the world's natural history collections are incorrectly named ${ }^{3}$. An urgent priority is,

66 therefore, to tackle the taxonomy of tropical plants from a global perspective.

67 DNA taxonomy was proposed 15 years ago as an alternative to morphology-based

68 taxonomy $^{17,18}$, which was dismissed as slow and over-reliant on a dwindling number of

69 experts ${ }^{9}$. Since then, DNA has played an increasingly important role in phylogeny

70 reconstruction and higher-level classifications of major lineages ${ }^{19,20}$, as well as in 
71 identification of existing species ${ }^{21,22}$, but it is only being used in an auxiliary capacity ${ }^{18}$, if at

72 all, for taxonomic revisions and monographs. Studies integrating DNA and morphology are

73 few and tend to avoid species-rich tropical groups where the greatest taxonomic problems

$74 \quad$ lie $^{7}$. Furthermore, there is no consensus on how DNA sequence data can be best used to solve

75 taxonomic problems at the species level.

76 This paper describes the integration of molecular phylogenetics with the morphological

77 study of living plants and herbarium collections to produce a taxonomic study of the

78 megadiverse genus Ipomoea L. (Convolvulaceae) — with an emphasis on the 423 species

79 described from the American continent. In parallel to the morphological study of herbarium

80 specimens from 72 European and American institutions, we sequenced DNA from 1,560 of

81 those specimens for several DNA barcodes. We also sequenced a subset of 384 samples,

82 representing 211 species, for the whole chloroplast genome and 605 putative single copy

83 nuclear regions using Hyb-Seq ${ }^{23}$ (Fig. 1). Integrating these two complementary sequencing

84 strategies alongside a comprehensive morphological study enabled us to exploit the resources

85 found in natural history collections and contribute to a diverse range of contemporary issues,

86 including the origin of a major crop, the temporal and spatial dynamics of how the New

87 World tropical flora was assembled, and the discovery of a substantial number of new

88 species.

89 TACKLING MEGADIVERSE GROUPS ON A GLOBAL SCALE

90 Present in all tropical and subtropical regions of the world, Ipomoea is among the

91 largest genera of plants ${ }^{24}$. The taxonomic knowledge of the genus at the beginning of our

92 project, in 2012, was relatively poor. The extensive literature and the existing taxonomy

93 contained as much error as valuable information, reflected in the fact that more than $50 \%$ of

94 Ipomoea names in GBIF, assigned to over 40,000 plant specimen records, are not currently

95 accepted (Supplementary Data File 1). Given this unsatisfactory situation, simple tasks such 
as identifying specimens, enumerating species from a particular country or preparing conservation assessments were problematic.

We based our approach to this comprehensive study of Ipomoea on the experience we had gained from a previous Foundation Monograph of Convolvulus ${ }^{25}$. We began our work by preparing a working checklist of all recognised species of Ipomoea (Supplementary Methods, Section 1) together with their commoner synonyms and their approximate distribution. Based on the distribution of individual species and their authors, we were able to predict which herbaria were likely to hold important collections of Ipomoea, including type specimens (Supplementary Methods, Sections 2 and 3). With a minimum estimate of 200,000 specimens of Ipomoea in the world's herbaria (Supplementary Methods, Section 2), obtaining all specimens on loan was neither practical nor necessary. Fortunately, we had ready access to large collections of Ipomoea at Kew Gardens (K) and the Natural History Museum in London (BM). By combining the study of specimens at these institutions with images in virtual herbaria and the insights of previous taxonomists (Supplementary Methods, Sections 3 and 4), we were able to determine important and useful taxonomic characters and thus begin to delimit species (Supplementary Methods, Section 5).

From the outset of the project, we aimed to integrate molecular and morphological data at all stages of the taxonomic process, each kind of data providing reciprocal illumination for many taxonomic decisions (Fig. 2).

Our approach was based on the idea that higher confidence for each species hypothesis is achieved when morphology and DNA barcodes — and genomic data when availablecorrelate, corroborating a species hypothesis. With this aim, and in parallel to our morphological studies, we started sequencing three DNA barcodes (nuclear ITS and chloroplast matK and $r b c L$ regions) from specimens available to us from our own collections, from $\mathrm{K}$ and $\mathrm{BM}$, an additional 45 other herbaria and individual sources (Supplementary 
121 Methods, Sections 6-8) (Extended Data Fig. 1) (Supplementary Data File 2). Our aim was to

122 include, when possible, several specimens of every species in the phylogenies, as well as un-

123 named specimens or specimens that we considered, from our morphological studies, to be

124 interesting or puzzling. From this extensive sampling strategy, we gradually developed a

125 provisional phylogenetic framework to inform species delimitation.

126 Given the time constraints and the large quantity of species we were trying to study, we

127 were unable to optimize conditions for extracting and sequencing DNA from intractable

128 specimens but, instead, opted to find alternative specimens or simply to move on. About one

129 and a half years into the project we decided to focus our barcode sequencing solely on ITS as

130 it had provided most resolution and the highest success in extracting and sequencing DNA (c.

$13160 \%$ specimens extracted were successfully amplified). We treated the ITS phylogeny

132 (Supplementary Data File 3) as a single taxonomic character and thus equivalent to a single

133 morphological character ${ }^{26}$ that might sometimes provide information for species delimitation

134 and sometimes not (Extended Data Fig. 2). In many cases, the ITS phylogeny corroborated a

135 species hypothesis based on morphology by showing it to be monophyletic. In other cases,

136 the ITS phylogeny also revealed that specimens a priori thought to be the same species were,

137 in reality, different taxa, in which case we re-evaluated the morphology and sequenced

138 additional specimens where these were available. For other species, the ITS phylogeny

139 provided little or no resolution, for example in the group of species most closely related to the

140 sweet potato (sometimes spelled sweetpotato), Ipomoea batatas (L.) Lam. In these cases, we

141 tested species hypotheses using genomic data ${ }^{27}$ (see below). If no genomic data were

142 available, we based our species delimitation on morphology only (Supplementary

143 Information, DNA barcodes as another taxonomic character).

144 We were nevertheless aware of the many limitations of single marker phylogenies ${ }^{28-30}$

145 and of the inability of ITS to provide a robust and independent phylogenetic framework for 
146 Ipomoea ${ }^{31-33}$. Our whole approach to the interpretation of the ITS phylogeny was, therefore,

147 one of extreme caution and, in addition, we had always planned to secure a greater amount of

148 sequence data using high-throughput sequencing. We used Hyb-Seq ${ }^{23}$ to obtain 605 nuclear

149 regions and the whole chloroplast genome of 384 samples of Ipomoea representing 211

150 species (Supplementary Methods, Section 8). These data allowed us to obtain more robust

151 phylogenies for Ipomoea (Extended Data Fig. 3 and Extended Data Files 4-8), to test the

152 accuracy of the ITS phylogeny and to critically evaluate species delimitation in relation to the

153 sweet potato and its closest relatives ${ }^{27}$. In summary, incorporating molecular phylogenetics

154 into the taxonomic process provided a phylogenetic structure for Ipomoea as well as insights

155 into species relationships, ultimately contributing to the taxonomic process at a number of

156 levels (Table 1 and Fig. 2).

157 Species delimitation proceeds by looking for discrete and correlated characters that

158 separate entities that are hypothesised to be 'separately evolving metapopulation lineages' 34 .

159 As the process of species delimitation is extended and complex, involving the integration of

160 morphology, DNA sequencing, previous literature, photographs and fieldwork, DNA

161 sequencing alone is not sufficient to underpin taxonomic decisions. In contrast, when

162 integrated with other sources of data it can be extremely powerful. We provide eight

163 examples to illustrate the process of species delimitation and taxonomic decision-making that

164 underpinned this work (Supplementary Information, Species Narratives).

\section{KEY TAXONOMIC RESULTS}

166 An accurate taxonomy of a plant group across its entire geographical distribution

167 enables the assembly of checklists and floras at different scales. Fig. 3a illustrates the power

168 and importance of continental-scale taxonomy conducted against the backdrop of a global

169 phylogenetic framework. This figure shows that the 109 species of Ipomoea known from

170 Bolivia ${ }^{35-37}-20$ of them described as new species during this project - are dispersed across 
171 the entire phylogeny of the genus, underlining the limitations of geographically restricted 172 studies.

173 The power of the global approach is also illustrated by the number of specimens that 174 required a name change as a result of our studies $-39 \%$ of specimens sequenced (Fig. 3b)

175 (see specific examples of species delimitations and synonymy in Supplementary Information, 176 Species Narratives). In addition to the large number of new identifications provided, we 177 described 63 new species, all of them dispersed throughout the phylogenetic breadth of 178 Ipomoea. Importantly, our contribution to the taxonomy of Ipomoea documented a 69\% 179 synonymy rate: seven out of every ten published names are synonyms ${ }^{38}$. In addition, we 180 lectotypified 274 names and published 423 descriptions, 257 new illustrations, 43 distribution 181 maps and 27 identification keys ${ }^{36-46}$.

182 Finally, our phylogenies confirm that many previously recognised segregated genera 183 are nested within Ipomoea ${ }^{31,47}$ (Extended Data Fig. 3) and that an expanded Ipomoea 184 containing these species is necessary to make the genus monophyletic (Supplementary 185 Information, Phylogeny of Ipomoea). New combinations for all names in other genera that 186 need transferring into Ipomoea are provided in Supplementary Information, Nomenclatural 187 changes.

\section{RAPID RADIATIONS IN IPOMOEA}

A by-product of our focus on species-level taxonomy and DNA sequencing was a comprehensively sampled phylogenetic framework for Ipomoea that provided valuable information at multiple levels. During our studies, we became aware of two very diverse clades within Ipomoea in which species morphologies overlap considerably and phylogenetic relationships are poorly resolved. One of these clades is concentrated in central South America (Paraguay, southeast Bolivia, southwest Brazil, and northern Argentina), whilst the other is more widespread in the Americas but with a particularly high concentration of 
species in the Caribbean region. These two diverse clades are closely related in our nuclear and chloroplast phylogenies, although the exact relationship differs between the two datasets (Extended Data Fig. 3a and b). In view of the unique characteristics of these two clades, we constructed a time-calibrated phylogeny for Ipomoea and estimated diversification rates throughout the genus (Fig. 4 and Extended Data Figs. 4-6). This showed that diversification rates were relatively constant in most of the genus, except for the part of the phylogeny that contained these two diverse clades (and a small number of other species). In this part of the phylogeny, there was initially a greater than 5.5-fold increase in net diversification rates compared to the background rate across the rest of the tree (an increase from 0.127 to 0.719 species $\mathrm{Myr}^{-1}$ ). Our analyses indicated that this was primarily a result of increased speciation rates, with extinction rates remaining relatively constant. Although our analysis indicated a diversification rate increase in the Lower Miocene, more recent phenomena might also influence the distinctive diversification dynamics in this part of the phylogeny, for example, many species in this part of the phylogeny occur exclusively in the Cerrado - a biome which probably only became established within the last $10 \mathrm{Myr}^{48,49}$ — and there are likely to have been numerous shifts into and out of this biome (Extended Data Fig. 7). Further, numerous shifts between different growth habits are also likely to have occurred between comparatively recently diverged lineages (Extended Data Fig. 7). A more densely sampled phylogeny is required to determine the nature of the relationship between biome occupancy and growth habit, and whether either of these two factors are likely to have promoted multiple nested diversification rate shifts, rather than the single rate increase reported here. Regardless, our results highlight an increase in net diversifications rates in Ipomoea that is likely to be of a similar scale to some of the most iconic evolutionary radiations in the plant kingdom ${ }^{50-53}$. Further, unlike many plant radiations, which are strongly associated with a transition into a particular biome, the radiation in Ipomoea occurs across a range of biomes, and in some 
cases, in areas that have been greatly disturbed by human actions. Further study of

222

223

224

\section{5}

diversification rate variation in Ipomoea, therefore, represents a promising avenue which could lead to fundamental insights into the effects of biome shifts and human disturbance on evolutionary diversification and the assembly of the Neotropical flora.

\section{EVOLUTION OF THE SWEET POTATO}

Most recent studies on the origin of the sweet potato (Ipomoea batatas (L.) Lam.) focus on the genetic variation contained within the $\mathrm{crop}^{54,55}$ or on the sequencing of whole genomes of the crop and one or two related species ${ }^{56,57}$. Meanwhile, the origin and evolution of the sweet potato and its relationship with its wild relatives (CWR) has only recently been clarified $^{27}$. The global study of the genus allowed us to identify all sweet potato CWR - two of them new species, I. lactifera J.R.I.Wood \& Scotland ${ }^{36}$ and I. australis (O’Donell) J.R.I.Wood \& P.Muñoz ${ }^{38}$ — and revealed the dual role of I. trifida (Kunth) G.Don, the closest wild relative, in the origin of the crop species ${ }^{27}$.

Previous studies have shown that sweet potato CWR do not produce storage $\operatorname{roots}^{58}$, so it has been assumed that the transition from non-storage root to storage root was mediated by human domestication ${ }^{33}$, although direct evidence for this claim remains elusive. However, our broad comparative study of the genus offers a novel perspective on the evolution of storage roots in Ipomoea and a very different narrative for the evolution of the sweet potato. At least 63 species of Ipomoea have been recorded in previous literature and our own observations as having storage roots, several of them edible and some bigger than the roots in I. batatas (Fig. 5a and Extended Data Table 1). Mapping species with storage roots onto a phylogeny shows that storage roots evolved multiple times independently from species that do not have storage roots (or these have never been recorded) (Fig. 5b).

We wanted to explore this question further and used our time-calibrated phylogenies to investigate the temporal dynamics of sweet potato. We set out to determine whether our data 
were consistent with sweet potato originating within the timeframe of human agriculture

247 (roughly the last 10,000 years) or if it was older. Our results indicated that the sweet potato

248 was likely to have diverged from its closest wild relative, Ipomoea trifida, over 1 million

249 years ago ${ }^{27}$ (Fig. 5b) and that part of the diversity existing within the crop largely pre-dated

250 the origin of agriculture (Fig. 6). This timeframe is consistent with the idea that the sweet

251 potato evolved long before the onset of human agriculture, and that the storage root was an

252 existing trait that favoured the species being taken into cultivation by humans. Further, all

253 other species with storage roots also evolved over 1 million years ago (Fig. 5b), many within

254 the timeframe associated with the expansion of $\mathrm{C} 4$ grasses and the evolution of fire-adapted

255 vegetation types ${ }^{48,49}$ in which underground storage organs would be advantageous. In

256 summary, the evidence presented here suggests that the storage root in cultivated sweet

257 potato is not a product of human domestication but rather an existing trait that predisposed

258 the plant for cultivation. To the best of our knowledge, this possibility has not been

259 previously considered.

260

261

262

263

264

265

266

267

268

269

\section{THE IMPORTANCE AND POTENTIAL OF TAXONOMIC MONOGRAPHY}

Taxonomic studies based on the massive number of natural history collections held

worldwide highlight the awesome complexity and wonder of the natural world. They merit a

more important role in the task of addressing a range of environmental issues from food

security, conservation and biodiversity inventories to ecology in general. The taxonomic

community itself needs to embrace and rediscover the value of taxonomic monographs ${ }^{25,59}$

within the context of what constitutes world-class science ${ }^{60}$. The full integration of two distinct skill sets, DNA sequencing and morphological studies, is necessary to achieve this.

Although other scientific subjects bring a unique perspective to environmental science, including evolution, ecology and population genetics, monographic taxonomy undertaken 
with modern methods at the global scale has the potential to play a vital role in the contemporary research agenda.

Taxonomy is often seen as a redundant science because of the mistaken idea that biodiversity is as well-known overall as it is in a few well-studied, high profile groups or countries. It is also undervalued by the inaccurate view that taxonomic knowledge steadily accumulates until all species of a particular group are discovered, whereas in reality names, synonyms, mistaken identifications and errors accumulate alongside accepted names and reliable information. This accretion needs to be sifted and new species identified to provide an accurate taxonomy, something that is lacking for the vast majority of tropical flowering plant genera of any reasonable size. With the rapid increase in the number of unstudied collections in the last fifty years, there is now a unique opportunity to embrace the challenges and opportunities that these specimens provide to produce taxonomically sound monographs of the plant diversity these natural history collections represent.

To fully exploit the opportunity and potential of global natural history collections, as undertaken in this study, demands the integration of different scientific expertise including specimen-based taxonomy, genomics and phylogenetics. This has implications for the type of training that the next generation of biodiversity scientists receive. It seems unrealistic to expect an individual scientist to be expert in all three disciplines but assembling small teams of people with such expertise to tackle the world's major taxonomic problems at a global scale is surely possible given existing resources and expertise. The skills and resources currently exist for many taxonomically diverse groups (and as long as taxonomic training continues or is increased) and we hope that this study acts as a catalyst in demonstrating the scale of progress that can be achieved in a realistic time-frame.

\section{METHODS}


In this section, we provide a summary of the methodology underlying our studies of

295

296

297

298

299

300

301

302

303

304

305

306

307

308

309

310

311

312

313

314

315

316

317

Ipomoea. We provide a detailed description of every step in the Supplementary Methods.

Although we report the morphology and molecular methods separately, they were, in fact, conducted in parallel and integrated throughout the process.

Herbarium and field work. We assembled a preliminary checklist from existing literature of all species of Ipomoea (Supplementary Methods, section 1) and identified herbaria that house significant collections that we would visit or from which we could obtain online images (Supplementary Methods, sections 2 and 3). Simultaneously, we surveyed morphological variation across the genus - with reference to existing literature as well as specimens - to identify taxonomically useful characters for species delimitation (Supplementary Methods, sections 4 and 5). We subsequently visited, received loans of material from or studied photographs from the following herbaria (acronyms according to ${ }^{61}$ ) in Europe (AAU, B, BM, C, CGE, E, G, GOET, K, L, LE, M, MA, OXF, P, PC, RBGE, S, TO and W), the United States (A, ARIZ, BISH, F, FTG, GA, GH, MICH, MO, NY, RSA, SELU, TEX, US and USDA), Latin America (Argentina: CTES, LIL; Bolivia: BOLV, HSB, LPB, USZ; Brazil: CEN, CPAP, CRIA, HEPH, HUEFS, IPA, JPB, MBM, PEUFR, R, RB, SP and UB; Colombia: COL; Cuba: HACB, HAJB; Mexico: IEB, MEXU; Panama: PAM; Paraguay: FCQ, PY, SCP; Peru: CIP, CUZ, USM), China (ISBC, KUN), South East Asia (Malaysia: KEP, SAN; Singapore: SING) and Australia (FRI). We studied the variation in all herbarium material seen and photographed and databased specimens (Supplementary Methods, Sections 2-5). We carried out fieldwork in Bolivia, Paraguay, Argentina and Brazil (Supplementary Methods, Section 6). We also developed a network of contacts with people interested in Ipomoea with whom we corresponded over a range of related issues (Supplementary Methods, Section 7). 
318 Analysis of DNA barcodes. The analyses using barcodes were based on 3,035 ITS, matK and trnH sequences from 1,560 specimens (Passport Data in Extended Data File 1) (Extended

321 Likelihood phylogenetic analyses in RAxML v. $8^{64}$, Approximate Maximum Likelihood in

322 FastTree $2^{65}$ and Bayesian inference in MrBayes $^{66}$ (Supplementary Methods, Section 8).

323 Analysis of genomic data. We obtained the whole chloroplast genome and 605 putative

324 single-copy nuclear coding regions from 385 specimens representing 211 species using Hyb-

$325 \mathrm{Seq}^{23}$ (Supplementary Methods, Section 8). These specimens were selected based on quality

326 and quantity of the available DNA with the aim of covering as much phylogenetic breadth as

327 possible. We ran phylogenetic analyses on both sets of genomic data. For the nuclear data, we

328 ran additional analyses using only the subset of 434 regions that passed the PHI

329 recombination test ${ }^{67}$. In addition, mapping our data to the recently published Ipomoea triloba

330 genome ${ }^{57}$ warned some of our regions may not be single copy; hence, we ran further analyses

331 using only the subset of 421 regions that we were confident are single copy (Supplementary

332 Methods, Section 8). We used Maximum Likelihood, Approximate Maximum Likelihood

333 and Bayesian Inference to analyse the chloroplast data. Regarding the nuclear coding regions,

334 we used Maximum Likelihood and Approximate Maximum Likelihood for the analysis of

335 concatenated alignments as well as inferred species trees from gene trees using coalescence

336 methods. All methods and datasets recovered the same major clades within Ipomoea and the

337 relationship between taxa within those clades was mostly congruent across phylogenies

338 (Supplementary Discussion, Phylogeny of Ipomoea).

339 Divergence time estimates. We estimated divergence times within Ipomoea in treePL ${ }^{68,69}$.

340 We used the nuclear NGS phylogeny inferred in FastTree $2^{65}$ as input tree. We used a

341 smoothing value of 0.01 following extensive cross-validation analyses (Supplementary

342 Methods, Section 9), but also experimented with different smoothing values $(0.01,1,100$, 
343 10000) to determine the sensitivity of divergence time estimates to different assumptions

344 about among-branch-rate-variation. We also inferred time-calibrated phylogenies with the

345 chloroplast phylogeny as the input tree. In this case, we also experimented with different

346 smoothing values $(0.01,1,100,10000)$. For these phylogenies, we used a point calibration

347 for the root node of 34.0 Myr. We consider this the most realistic age estimate for Ipomoea,

348 following a series of analyses in which we experimented with different methods for

349 calibrating a phylogeny for Convolvulaceae and Solanaceae. The analyses for

350 Convolvulaceae and Solanaceae were performed in RevBayes ${ }^{70}$ (Supplementary Methods,

351 Section 9).

352 We used $\mathrm{BAMM}^{71}$ to infer diversification rates. The time-calibrated phylogeny inferred

353 from nuclear genomic data in treePL ${ }^{69}$ was used as the input phylogeny. When performing

354 this analysis, we specified clade specific sampling fractions. These were taken into account

355 when estimating diversification rates. We performed several supplementary diversification

356 rate analyses. These used the different time-calibrated phylogenies outlined above as input

357 phylogenies (Supplementary Methods, Section 9).

\section{Data availability}

359 Passport data of all specimens included in the molecular studies presented in this paper

360 is available in Extended Data File 2. Additional records and information of the collections

361 included in this study and of specimens added subsequently are available through the project

362 website (https://herbaria.plants.ox.ac.uk/bol/ipomoea). DNA barcode sequences are available

363 through GenBank and genome assemblies are available through the Oxford Repository

364 Archive (https://doi.org/10.5287/bodleian:kepgnxzeK). Illumina raw reads are available

365 through the Sequence Read Archive (BioProject PRJNA453382). Alignment files and other

366 materials are available from the corresponding author upon request.

\section{REFERENCES}


368 1. Brownsey, P. The Banks and Solander collections - a benchmark for understanding the

369 New Zealand flora. J. R. Soc. N. Z. 42, 131-137 (2012).

370 2. Mabberley, D. J. Jupiter botanicus: Robert Brown of the British Museum. (J. Cramer ;

371 British Museum (Natural History), 1985).

372 3. Goodwin, Z. A., Harris, D. J., Filer, D., Wood, J. R. I. \& Scotland, R. W. Widespread

373 mistaken identity in tropical plant collections. Curr. Biol. 25, R1066-R1067 (2015).

374 4. The Science and Technology Committee, House of Lords. Systematics and Taxonomy in

$375 \quad$ crisis. 386 (Authority of the House of Lords, 2008).

376 5. Riedel, A., Sagata, K., Suhardjono, Y. R., Tänzler, R. \& Balke, M. Integrative taxonomy

377 on the fast track - towards more sustainability in biodiversity research. Front. Zool. 10,

$378 \quad 15(2013)$

379 6. Bradley, R. D., Bradley, L. C., Garner, H. J. \& Baker, R. J. Assessing the value of natural 380 history collections and addressing issues regarding long-term growth and care.

$381 \quad$ BioScience 64, 1150-1158 (2014).

382 7. CBD. Plant Conservation Report. A review of progress in implementing the Global

383 Strategy for Plant Conservation (GSPC). 50 (Convention on Biological Diversity, 2009).

384 8. Feeley, K. J. \& Silman, M. R. The data void in modeling current and future distributions 385 of tropical species. Glob. Change Biol. 17, 626-630 (2011).

386 9. Scotland, R. W. \& Wood, J. R. I. Accelerating the pace of taxonomy. Trends Ecol. Evol.

$387 \quad 27,415-416(2012)$.

388 10. Bisby, F. A., Shimura, J., Ruggiero, M., Edwards, J. \& Haeuser, C. Taxonomy, at the $389 \quad$ click of a mouse. Nature 418, 367-367 (2002).

390 11. Joppa, L. N., Roberts, D. L. \& Pimm, S. L. The population ecology and social behaviour 391 of taxonomists. Trends Ecol. Evol. 26, 551-553 (2011). 
392

393

394

395

396

397

398

399

400

401

402

403

404

405

406

407

408

409

410

411

412

413

414

415

12. Bacher, S. Still not enough taxonomists: reply to Joppa et al. Trends Ecol. Evol. 27, 6566 (2012).

13. Wheeler, Q. D. et al. Mapping the biosphere: exploring species to understand the origin, organization and sustainability of biodiversity. Syst. Biodivers. 10, 1-20 (2012).

14. Costello, M. J., May, R. M. \& Stork, N. E. Can we name Earth's species before they go extinct? Science 339, 413-416 (2013).

15. Bebber, D. P., Wood, J. R. I., Barker, C. \& Scotland, R. W. Author inflation masks global capacity for species discovery in flowering plants. New Phytol. 201, 700-706 (2014).

16. Wortley, A. H. \& Scotland, R. W. Synonymy, sampling and seed plant numbers. TAXON 53, 478-480 (2004).

17. Tautz, D., Arctander, P., Minelli, A., Thomas, R. H. \& Vogler, A. P. DNA points the way ahead in taxonomy. Nature 418, 479-479 (2002).

18. Tautz, D., Arctander, P., Minelli, A., Thomas, R. H. \& Vogler, A. P. A plea for DNA taxonomy. Trends Ecol. Evol. 18, 70-74 (2003).

19. Chase, M. W. et al. Phylogenetics of seed plants: an analysis of nucleotide sequences from the plastid gene rbcL. Ann. Mo. Bot. Gard. 80, 528 (1993).

20. THE ANGIOSPERM PHYLOGENY GROUP*. An update of the Angiosperm Phylogeny Group classification for the orders and families of flowering plants: APG II. Bot. J. Linn. Soc. 141, 399-436 (2003).

21. Hollingsworth, P. M., Li, D.-Z., van der Bank, M. \& Twyford, A. D. Telling plant species apart with DNA: from barcodes to genomes. Philos. Trans. R. Soc. B Biol. Sci. 371, 20150338 (2016).

22. CBOL Plant Working Group et al. A DNA barcode for land plants. Proc. Natl. Acad. Sci. 106, 12794-12797 (2009). 
416 23. Weitemier, K. et al. Hyb-Seq: combining target enrichment and genome skimming for 417 plant phylogenomics. Appl. Plant Sci. 2, 1400042 (2014).

418 24. Frodin, D. G. History and concepts of big plant genera. Taxon 53, 753 (2004).

419

25. Wood, J. et al. A foundation monograph of Convolvulus L. (Convolvulaceae). PhytoKeys $420 \quad 51,1-282(2015)$.

421 26. Doyle, J. J. Gene trees and species trees: molecular systematics as one-character 422 taxonomy. Syst. Bot. 17, 144 (1992).

423 27. Muñoz-Rodríguez, P. et al. Reconciling conflicting phylogenies in the origin of sweet 424 potato and dispersal to Polynesia. Curr. Biol. 28, 1246-1256.e12 (2018).

425

28. Baldwin, B. G. Phylogenetic utility of the Internal Transcribed Spacers of nuclear ribosomal DNA in plants: an example from the Compositae. Mol. Phylogenet. Evol. 1, 316 (1992).

29. Álvarez, I. \& Wendel, J. F. Ribosomal ITS sequences and plant phylogenetic inference. Mol. Phylogenet. Evol. 29, 417-434 (2003).

30. Feliner, G. N. \& Rosselló, J. A. Better the devil you know? Guidelines for insightful utilization of nrDNA ITS in species-level evolutionary studies in plants. Mol. Phylogenet. Evol. 44, 911-919 (2007).

31. Miller, R. E., Rausher, M. D. \& Manos, P. S. Phylogenetic systematics of Ipomoea (Convolvulaceae) based on ITS and Waxy sequences. Syst. Bot. 24, 209-227 (1999).

32. Huang, J., Corke, H. \& Sun, M. Highly polymorphic AFLP markers as a complementary tool to ITS sequences in assessing genetic diversity and phylogenetic relationships of sweetpotato (Ipomoea batatas (L.) Lam.) and its wild relatives. Genet. Resour. Crop Evol. 49, 541-550 (2002).

33. Roullier, C. et al. Disentangling the origins of cultivated sweet potato (Ipomoea batatas (L.) Lam.). PLoS ONE 8, e62707 (2013). 
34. De Queiroz, K. Species concepts and species delimitation. Syst. Biol. 56, 879-886 (2007).

35. Wood, J. R. I., Bianchini, R. S. \& Fuentes, A. F. Convolvulaceae. in Catálogo de las plantas vasculares de Bolivia (eds. Jorgensen, P. M., Nee, M. H. \& Beck, S. G.) 520-531 (Missouri Botanical Garden Press, 2015).

36. Wood, J. R. I. et al. Ipomoea (Convolvulaceae) in Bolivia. Kew Bull. 70, 71 (2015).

37. Wood, J. R. I., Martinez Ugarteche, M. T., Muñoz-Rodríguez, P. \& Scotland, R. W. Additional notes on Ipomoea (Convolvulaceae) in Bolivia. Kew Bull. 73, 57 (2018).

38. Wood, J. R. I., Muñoz-Rodríguez, P., Williams, B. R. M. \& Scotland, R. W. A foundation monograph of Ipomoea (Convolvulaceae) in the New World. Submitted (2019).

39. Wood, J. R. I., de Arrúa, R. D., de Rojas, G. D. \& Scotland, R. W. Two overlooked species of Ipomoea L. (Convolvulaceae) from Paraguay. Kew Bull. 71, 25 (2016).

40. Wood, J. R. I., Urbanetz, C. \& Scotland, R. W. Ipomoea pantanalensis, a new species of Ipomoea L. (Convolvulaceae) from the Pantanal, Brazil. Kew Bull. 71, 6 (2016).

41. Wood, J. R. I. \& Scotland, R. W. Notes on Ipomoea L. (Convolvulaceae) in Cuba and neighbouring islands with a checklist of species found in Cuba. Kew Bull. 72, 45 (2017).

42. Wood, J. R. I. \& Scotland, R. W. Misapplied names, synonyms and new species of Ipomoea (Convolvulaceae) from South America. Kew Bull. 72, 9 (2017).

43. Wood, J. R. I. \& Scotland, R. W. Notes on Ipomoea (Convolvulaceae) from the Amazonian periphery. Kew Bull. 72, (2017).

44. Wood, J. R. I., Muñoz-Rodríguez, P., Degen, R. \& Scotland, R. W. New species of Ipomoea (Convolvulaceae) from South America. PhytoKeys 88, 1-38 (2017). 
464

465

466

467

468

469

470

471

472

473

474

475

476

477

478

479

480

481

482

483

484

485

486

45. Wood, J. R. I., Buril, M. T. \& Scotland, R. W. Remarkable disjunctions in Ipomoea species (Convolvulaceae) from NE Brazil and Central America and their taxonomic implications. Kew Bull. 72, 44 (2017).

46. Wood, J. R. I., Vasconcelos, L. V., Simão-Bianchini, R. \& Scotland, R. W. New species of Ipomoea (Convolvulaceae) from Bahia. Kew Bull. 72, (2017).

47. Wilkin, P. A morphological cladistic analysis of the Ipomoeeae (Convolvulaceae). Kew Bull. 54, 853-876 (1999).

48. Beerling, D. J. \& Osborne, C. P. The origin of the savanna biome. Glob. Change Biol. 12, 2023-2031 (2006).

49. Scheiter, S. et al. Fire and fire-adapted vegetation promoted C4 expansion in the late Miocene. New Phytol. 195, 653-666 (2012).

50. Baldwin, B. G. \& Sanderson, M. J. Age and rate of diversification of the Hawaiian silversword alliance (Compositae). Proc. Natl. Acad. Sci. 95, 9402-9406 (1998).

51. Hughes, C. \& Eastwood, R. Island radiation on a continental scale: exceptional rates of plant diversification after uplift of the Andes. Proc. Natl. Acad. Sci. 103, 10334-10339 (2006).

52. Givnish, T. J. et al. Origin, adaptive radiation and diversification of the Hawaiian lobeliads (Asterales: Campanulaceae). Proc. R. Soc. B Biol. Sci. 276, 407-416 (2009).

53. Koenen, E. J. M. et al. Exploring the tempo of species diversification in legumes. South Afr. J. Bot. 89, 19-30 (2013).

54. Zhang, D., Cervantes, J., Huamán, Z., Carey, E. \& Ghislain, M. Assessing genetic diversity of sweet potato (Ipomoea batatas (L.) Lam.) cultivars from tropical America using AFLP. Genet. Resour. Crop Evol. 47, 659-665 (2000). 
55. Roullier, C., Kambouo, R., Paofa, J., McKey, D. \& Lebot, V. On the origin of sweet potato (Ipomoea batatas (L.) Lam.) genetic diversity in New Guinea, a secondary centre of diversity. Heredity 110, 594-604 (2013).

56. Yang, J. et al. Haplotype-resolved sweet potato genome traces back its hexaploidization history. Nat. Plants 3, 696-703 (2017).

57. Wu, S. et al. Genome sequences of two diploid wild relatives of cultivated sweetpotato reveal targets for genetic improvement. Nat. Commun. 9, (2018).

58. Austin, D. F. The Ipomoea batatas Complex-I. Taxonomy. Bull. Torrey Bot. Club 105, 114-129 (1978).

59. Harris, D. J. \& Wortley, A. H. Monograph of Aframomum (Zingiberaceae). (The American Society of Plant Taxonomists, 2018).

60. Drew, L. W. Are we losing the science of Taxonomy? As need grows, numbers and training are failing to keep up. BioScience 61, 942-946 (2011).

61. Thiers, B. Index Herbariorum: a global directory of public herbaria and associated staff. (2018).

62. Katoh, K. MAFFT: a novel method for rapid multiple sequence alignment based on fast Fourier transform. Nucleic Acids Res. 30, 3059-3066 (2002).

63. Katoh, K. \& Standley, D. M. MAFFT multiple sequence alignment software version 7: improvements in performance and usability. Mol. Biol. Evol. 30, 772-780 (2013).

64. Stamatakis, A. RAxML version 8: a tool for phylogenetic analysis and post-analysis of large phylogenies. Bioinformatics 30, 1312-1313 (2014).

65. Price, M. N., Dehal, P. S. \& Arkin, A. P. FastTree 2 - Approximately MaximumLikelihood trees for large alignments. PLoS ONE 5, e9490 (2010).

66. Ronquist, F. et al. MrBayes 3.2: efficient bayesian phylogenetic inference and model choice across a large model space. Syst. Biol. 61, 539-542 (2012). 
512 67. Bruen, T. C. A simple and robust statistical test for detecting the presence of

513 recombination. Genetics 172, 2665-2681 (2005).

514 68. Sanderson, M. J. Estimating absolute rates of molecular evolution and divergence times:

515 a penalized likelihood approach. Mol. Biol. Evol. 19, 101-109 (2002).

516 69. Smith, S. A. \& O’Meara, B. C. treePL: divergence time estimation using penalized

517 likelihood for large phylogenies. Bioinformatics 28, 2689-2690 (2012).

518 70. Hohna, S. et al. RevBayes: bayesian phylogenetic inference using graphical models and

519 an interactive model-specification language. Syst. Biol. 65, 726-736 (2016).

520 71. Rabosky, D. L. Automatic detection of key innovations, rate shifts, and diversity-

521 dependence on phylogenetic trees. PLOS ONE 9, e89543 (2014).

\section{ACKNOWLEDGEMENTS}

523 Correspondence and requests for materials should be addressed to

524 robert.scotland@plants.ox.ac.uk.

525 We acknowledge the financial support of The Leverhulme Trust for our Ipomoea

526 Foundation Monograph project and the University of Oxford through The John Fell Fund for

527 travel and sequencing costs. P.M.R. was funded by a BBSRC scholarship granted through the

528 Interdisciplinary Bioscience DTP Programme and by the University of Oxford Global

529 Challenges Research Fund; he also received additional funding from a Santander Travel

530 Award and from the Synthesys project (FR-TAF-6575). J.R.I.W. received travel awards from

531 the Synthesis project to visit Paris (FR-TAF), Madrid (ES-TAF) and Stockholm (SE-TAF)

532 and B.R.M.W. received a Synthesis travel award to visit Leiden (NF-TAF). R.W.S. and

533 P.M.R. acknowledge funding from the BBSRC GCRF-IAA fund (BB/GCRF-IAA/16 and

534 BB/GCRF-IAA/17/16). T.C. was funded by a NERC scholarship granted through the

535 Environmental Research DTP Programme. We thank all herbarium curators for granting

536 access to their collections. We thank Tom Wells for his comments on the genomic analyses. 
537 We also thank all colleagues who contributed to this project through fieldwork and

538 continuous discussion (see list in Supplementary Information, Section 7).

\section{AUTHOR CONTRIBUTIONS}

540 Conceptualization, supervision and project administration, R.W.S.; Funding acquisition,

541 R.W.S., J.R.I.W., P.M.R. and T.C.; Methodology, R.W.S., J.R.I.W., A.L., S.K., K.W., B.K.,

542 D.H, D.F., P.M.R. and T.C.; Resources, J.R.I.W., B.R.M.W., P.M.R., A.S., Z.G., N.L.A. and

543 M.D.R.; Formal analysis and investigation, P.M.R., T.C. and J.R.I.W.; Writing - original

544 draft, P.M.R., R.W.S., T.C. and J.R.I.W.; Writing - reviewing and editing, all authors;

545 Visualization, P.M.R.

\section{AUTHOR INFORMATION}

547 Reprints and permissions information is available at www.nature.com/reprints.

548 The authors declare no competing interests. 
549 Fig. 1 | Natural history collections facilitate biodiversity studies at a global scale. This

550 map shows where the 1,560 herbarium specimens sequenced during our study of Ipomoea

551 were collected. Dots indicate the collection locality of specimens sequenced for DNA

552 barcoding; green dots indicate the subset of specimens that were also sequenced using Hyb-

553 Seq to obtain genomic-scale data.

554

555 Fig. 2 | Integrating morphology and DNA in global taxonomic studies is key to utilizing

556 the resources of natural history collections. The study of plant groups across their entire

557 geographical distribution results in an accurate taxonomy that enables the assembly of

558 national and regional checklists and floras, and also provides an essential framework for

559 subsequent evolutionary studies, conservation assessments and research on crop wild

560 relatives and food security.

561

562 Fig. 3 | Megadiverse plant groups demand a global approach. a) Nuclear genomic

563 phylogeny showing that the species recorded from Bolivia (green boxes) are scattered across

564 the phylogeny of the genus, which has a global distribution. b) ITS phylogeny of Ipomoea.

565 Red branches indicate specimens also sequenced using high-throughput sequencing. Black

566 boxes indicate specimens that we sequenced that changed their identification during our

567 studies, approximately 39\% of them. Many more specimens not included in our molecular

568 analyses also required a change of name.

569

570 Fig. 4 | Rapid radiations in Ipomoea. A time-calibrated phylogeny of Ipomoea, with

571 branches coloured according to the inferred speciation rate. The map indicates the geographic

572 distribution of two species rich clades, the species within which exhibit highly overlapping 
573 morphologies. Both of these two diverse clades (and a small number of other species) are part

574 of a larger clade in which speciation rates are significantly higher than the rest of Ipomoea.

575

576 Fig. 5 | Storage roots evolved multiple times independently in Ipomoea. a) Storage roots

577 in Ipomoea lilloana (top picture) are as big as those in the sweet potato (below); b) Time-

578 calibrated nuclear ML phylogeny highlighting the position of 30 species with storage roots,

579 indicated by red branches and dots. All these species originated at least $1 \mathrm{Mya}$. We have

580 recorded an additional 33 species with storage roots for which we do not have genomic data.

581 Fig. 6 | Diversity within sweet potato predates agriculture. Time-calibrated phylogenies

582 for sampled specimens of Ipomoea batatas and its closest relative Ipomoea trifida. The

583 divergence times indicate when lineages represented by different specimens are likely to have

584 diverged. Divergence times inferred using a) nuclear (NGS) data and b) whole chloroplast

585 genome data. The two Ipomoea batatas clades in b) correspond to the two chloroplast

586 lineages hypothesized in reference 27.

587 


\section{Table 1 | Contribution of the DNA to the taxonomic decision process}

\section{At the species level taxonomy, DNA has...}

1) Confirmed the monophyly of many species.

2) Drawn attention to the existence of unrecognised new species

3) Shown some species thought to be distinct are conspecific with others from different geographical areas, e.g. Ipomoea acanthocarpa from Africa with I. piurensis from America or I. lindenii from mainland America with the Jamaican endemic I. cyanantha.

4) Shown that some species sometimes thought to be the same are distinct, e.g. I. paludicola and I. asarifolia, I. huayllae and I. aristolochiifolia, I. jalapa and I. pterocaulis, etc.

5) Revealed wrongly identified specimens as they appear in parts of the phylogeny away from the clade with which they had been identified.

6) Provided a phylogenetic context to interpret morphology when specimens were poorly preserved.

\section{Regarding evolutionary relationships between species, DNA has...}

1) Revealed the existence of several clades and radiations.

2) Confirmed the monophyly of some groups previously recognised on morphological grounds such us Pharbitis, Quamoclit, Astripomoea and Batatas.

3) Shown that all previously recognised genera of the tribe Ipomoeeae (Argyreia, Stictocardia, etc.) are nested within Ipomoea and all but Astripomoea are not monophyletic.

4) Demonstrated that Rivea is nested within the clade dominated by Argyreia species.

5) Shown that some groups previously recognised are only monophyletic if certain species are excluded (e.g. Arborescens group).

6) Clarified the relationship between the sweet potato and its wild relatives and discovered two new species within this group. 
$\infty_{0}$

$x$

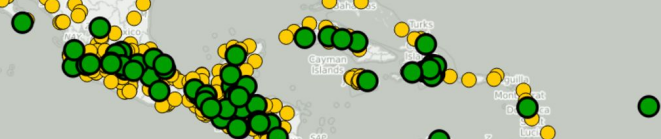

3080\%:

- 8

$\therefore 0.080 .88$

to

.

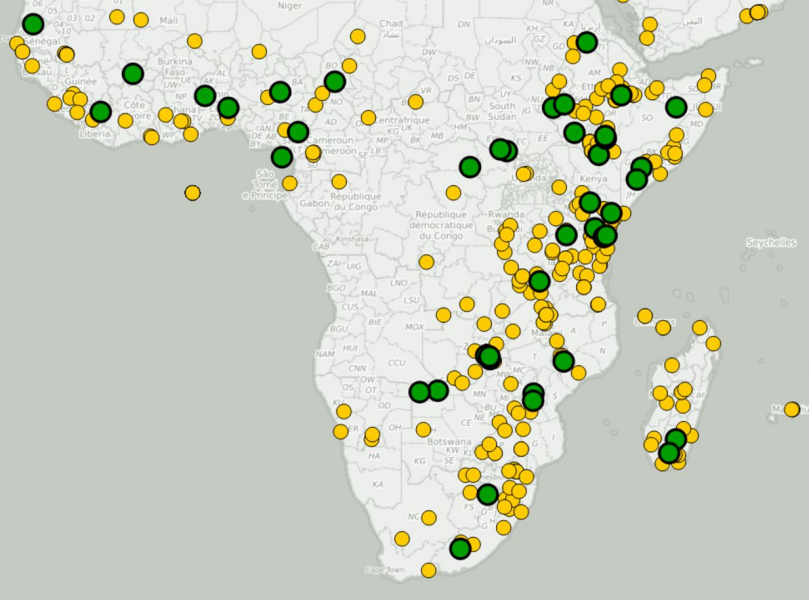

080

- $80^{\circ}$

68
0
80

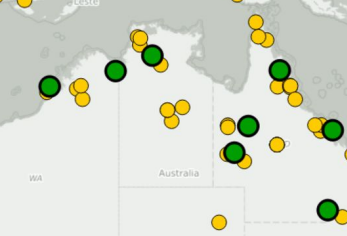




\section{EXISTING DATA}

\section{HERBARIUM \& FIELD WORK}

\begin{tabular}{|c|}
\hline $\begin{array}{l}\text { ASSEMBLE REPRESENTATIVE } \\
\text { SET OF SPECIMENS }\end{array}$ \\
\hline$\eta$ \\
\hline $\begin{array}{l}\text { MORPHOLOGICAL } \\
\text { STUDY }\end{array}$ \\
\hline$\nabla$ \\
\hline $\begin{array}{c}\text { GENERATION OF } \\
\text { SPECIES HYPOTHESES }\end{array}$ \\
\hline
\end{tabular}
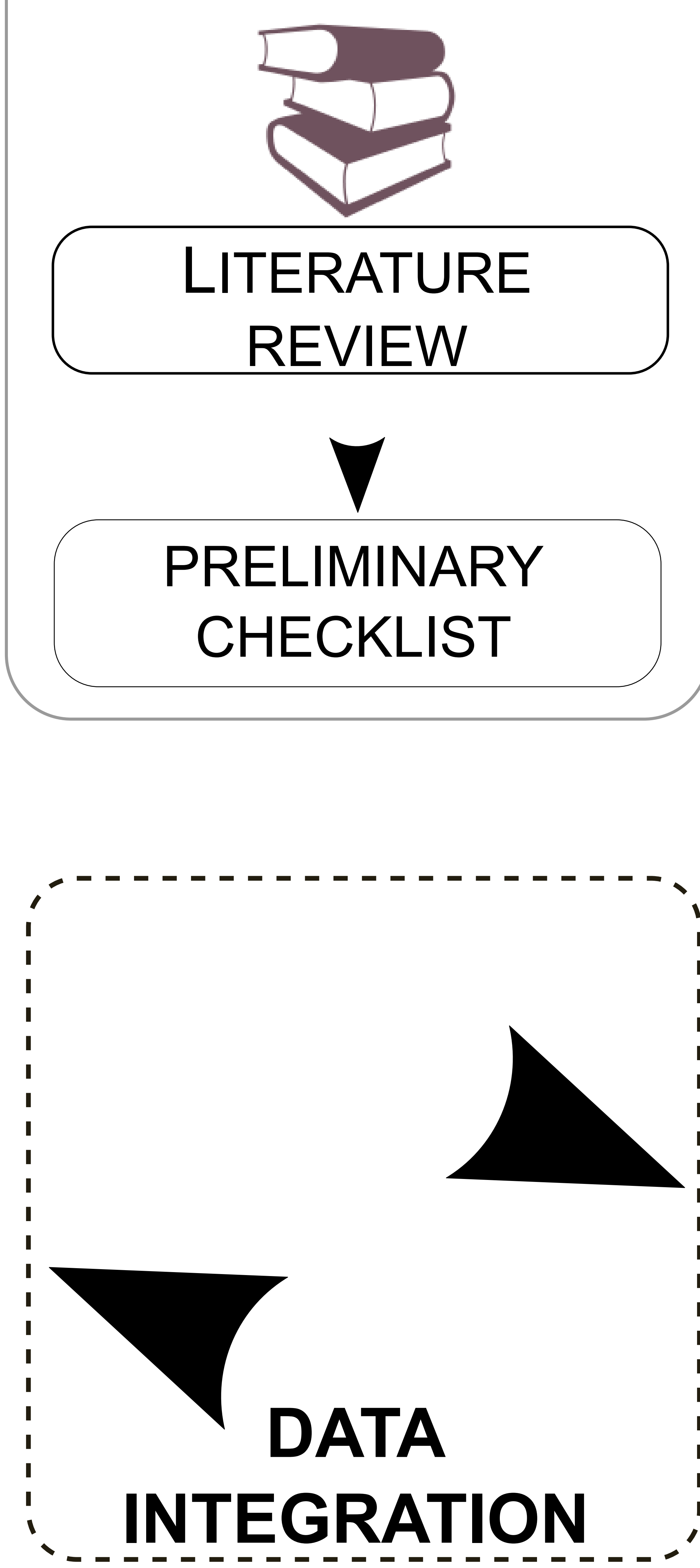

UPDATE NOMENCLATURE, TYPIFICATION, IDENTIFICATION KEYS, DESCRIPTIONS, ETC.
Subset of specimens

\section{LAB WORK}

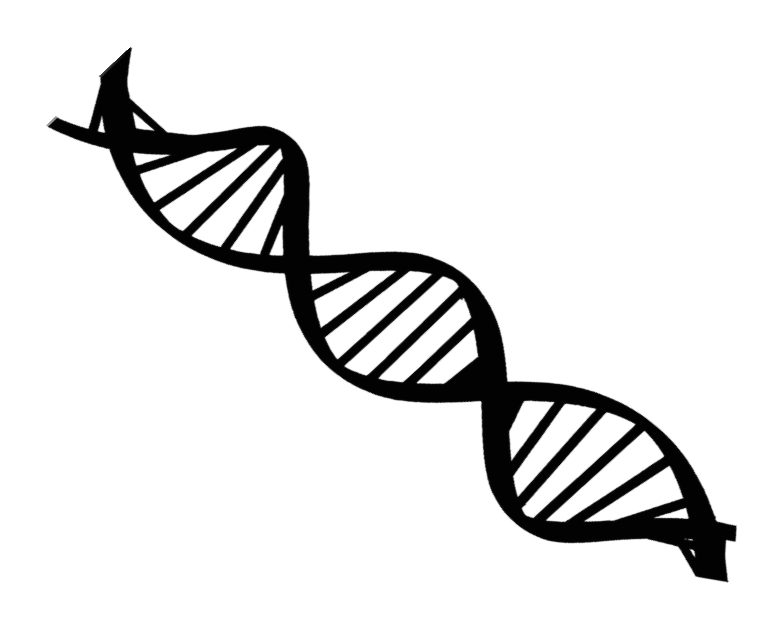

DNA EXTRACTION

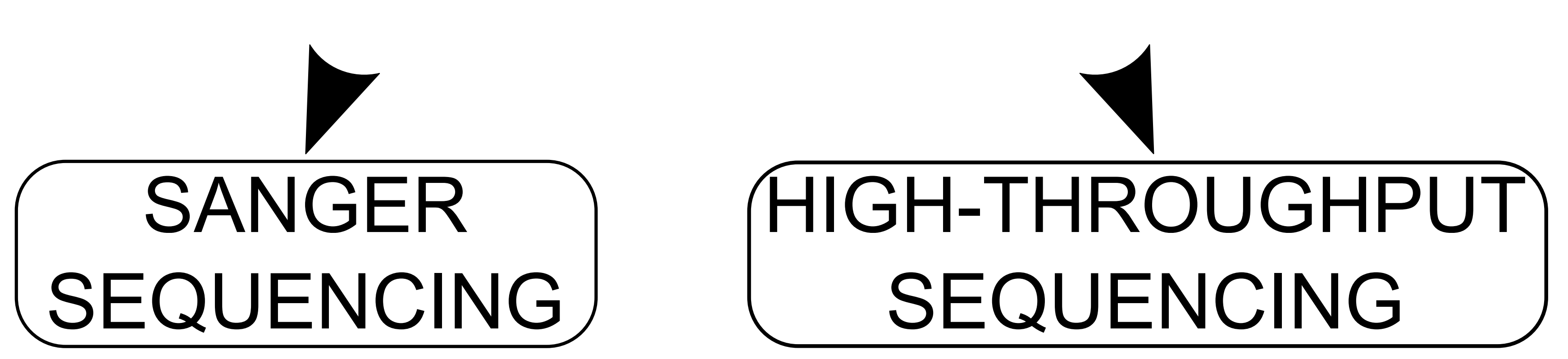

\section{Independent}

$\nabla$ test of accuracy $\nabla$

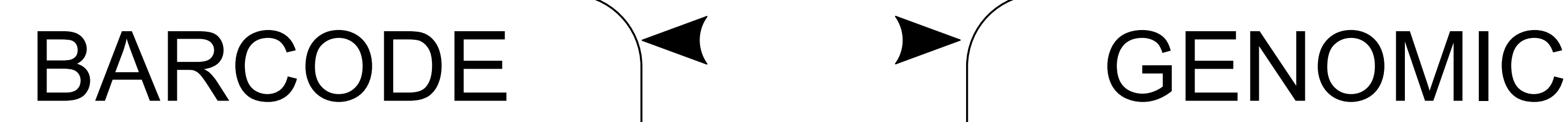
PHYLOGENIES

\section{PHYLOGENIES}

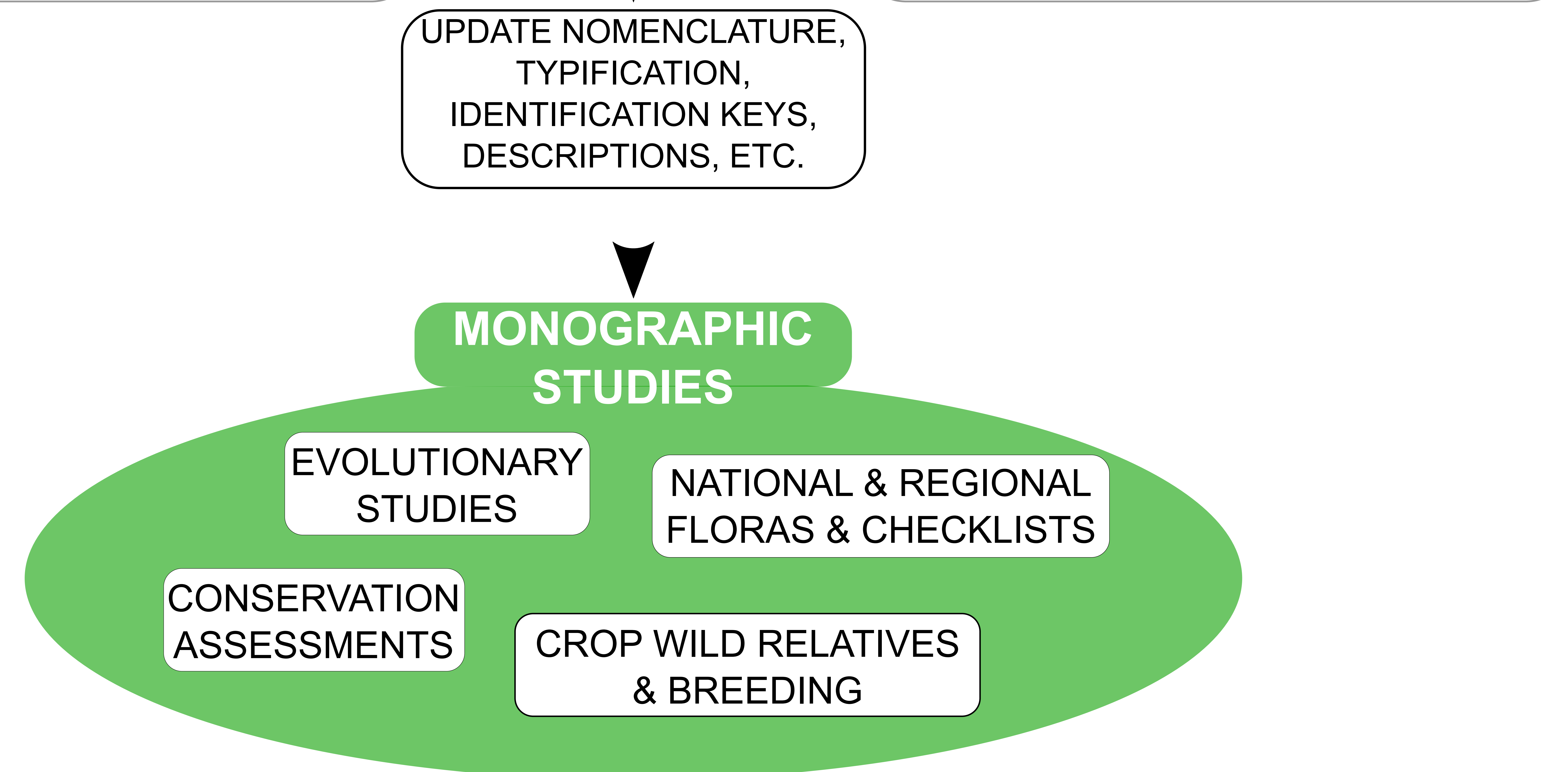


1. Ipomoea malvaeoides (2.2 Mya)

2. I. hieronymi (1.01)

3. I. lilloana (2.6)

4. I. jalapa (3.3)

5. I. descolei (4.2)

6. I. polpha (3.5)

7. I. mauritiana (2.9)

8. I. bonariensis (3.7)

9. I. pintoi (5.3)

10. I. batatas (2.6)

11. I. pubescens $(5.3)$

12. I. ampullacea (5.0)

13. I. orizabensis (2.2)

14. I. ancisa (3.0)

15. I. sescossiana (3.0)
16. I. stans (5.7)

17. I. muricata (4.5)

18. I. capillacea (3.6)

19. I. plummerae (3.6)

20. I. bracteata (3.99)

21. I. argillicola (2.9)

22. I. leptophylla (4.9)

23. I. pandurata (4.9)

24. I. cairica (8.1)

25. I. weltischii (9.1)

26. I. oenotherae (9.4)

27. Turbina bracteata (6.6)

28. I. holubii ( $=$ T. holubii) (5.2)

29. I. alpina (11.8)

30. Argyreia bracteata (11.7)

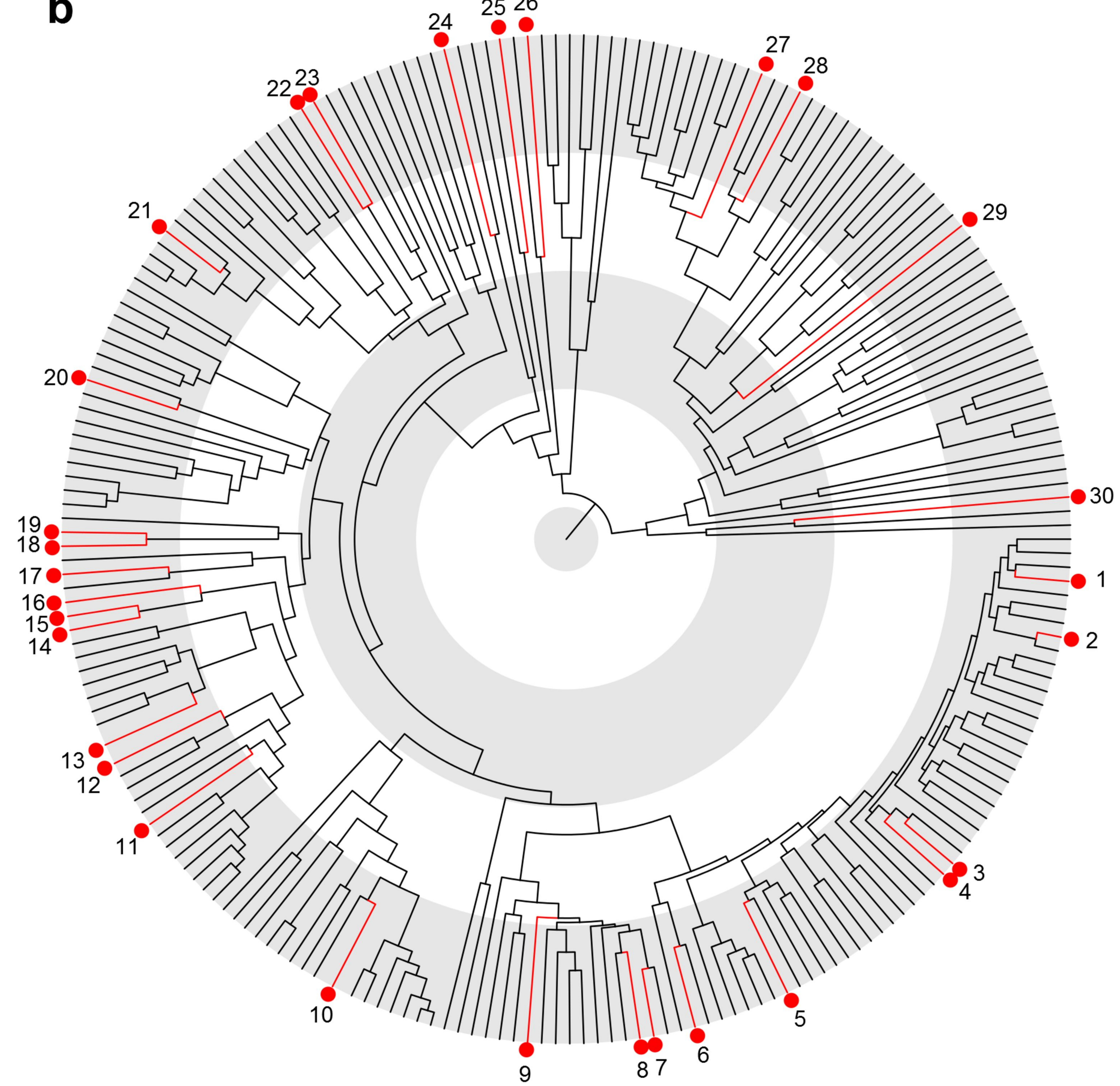


1844

1839

1834

1829

1824

1819

1814

1809

1804

1799

1794

1789

1784

1779

1774

1769

b NUMBER OF SPECIMENS SEQUENCED

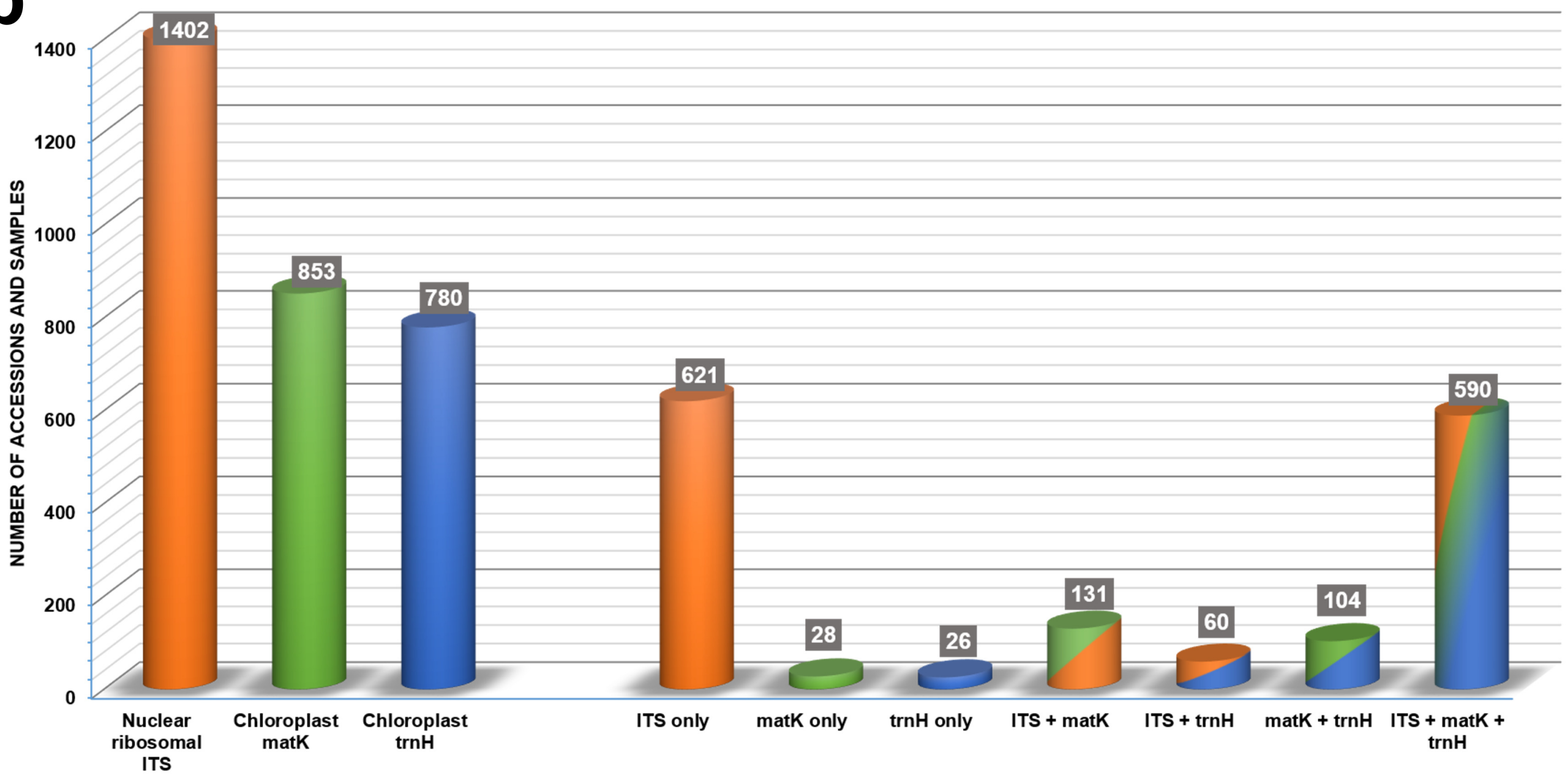


a. $\quad$ Smoothing $=1$
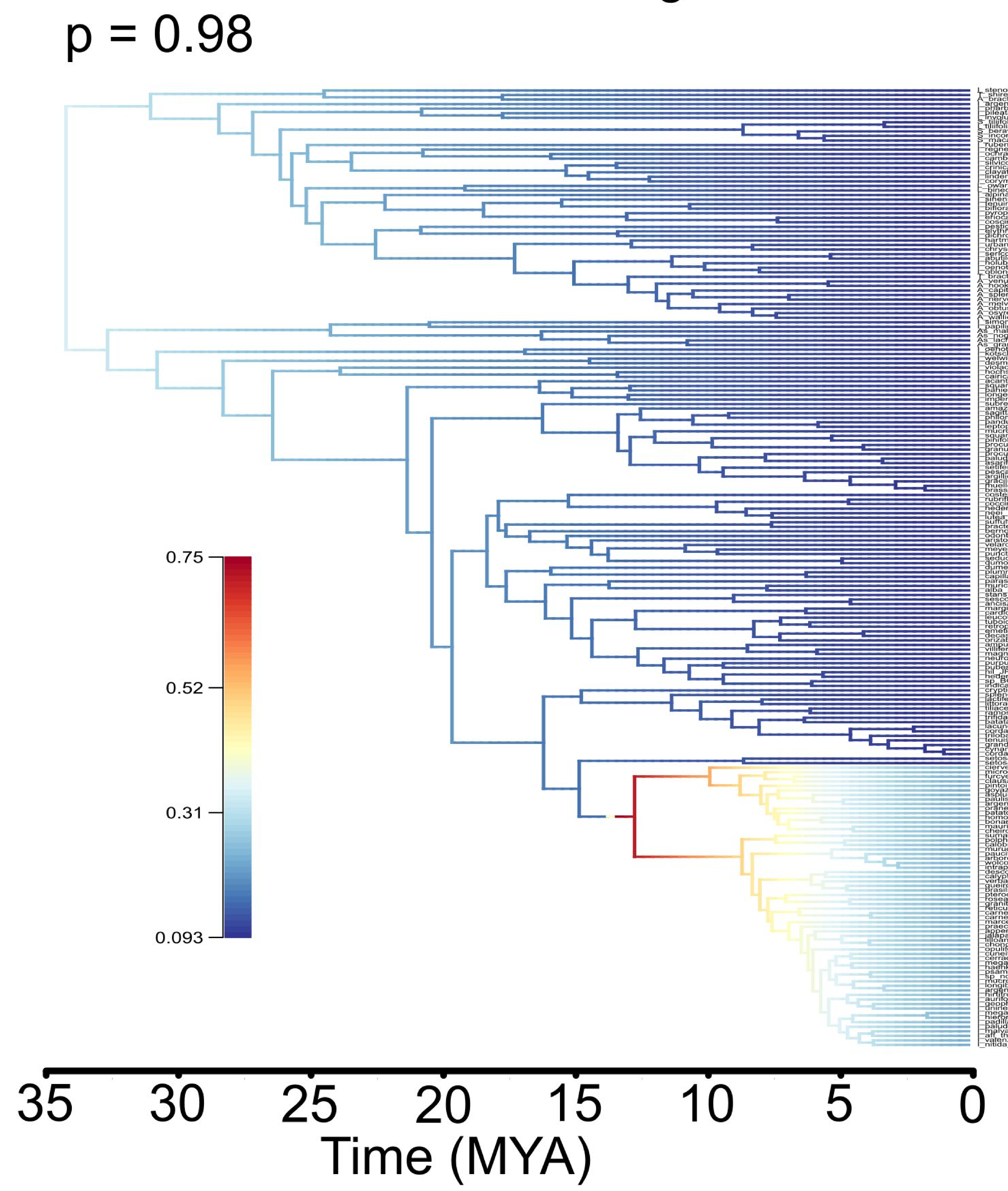

b. $\quad$ Smoothing $=100$

$p=0.98$
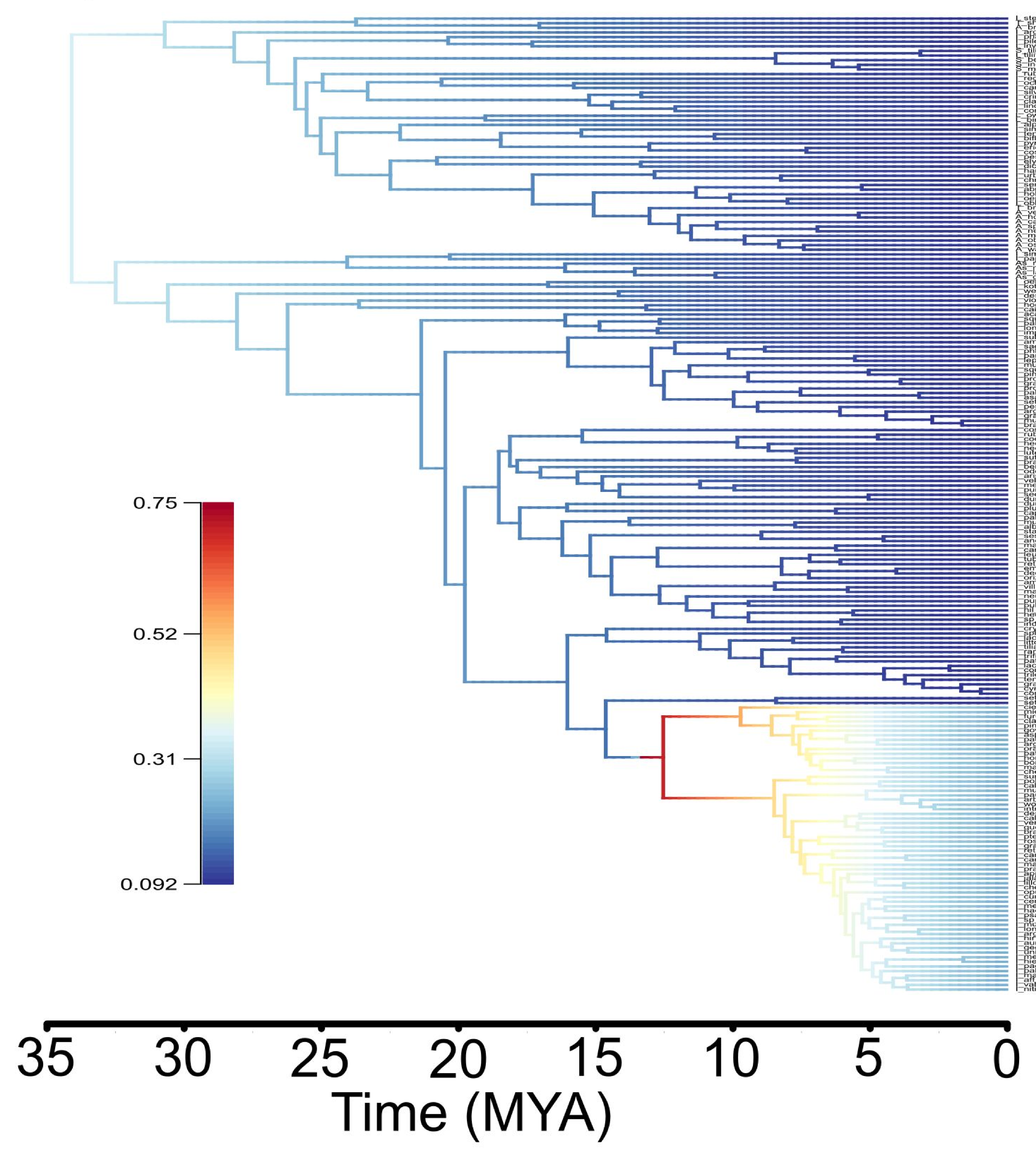

$c$.
$p=0.98 \quad$ Smoothing $=10000$

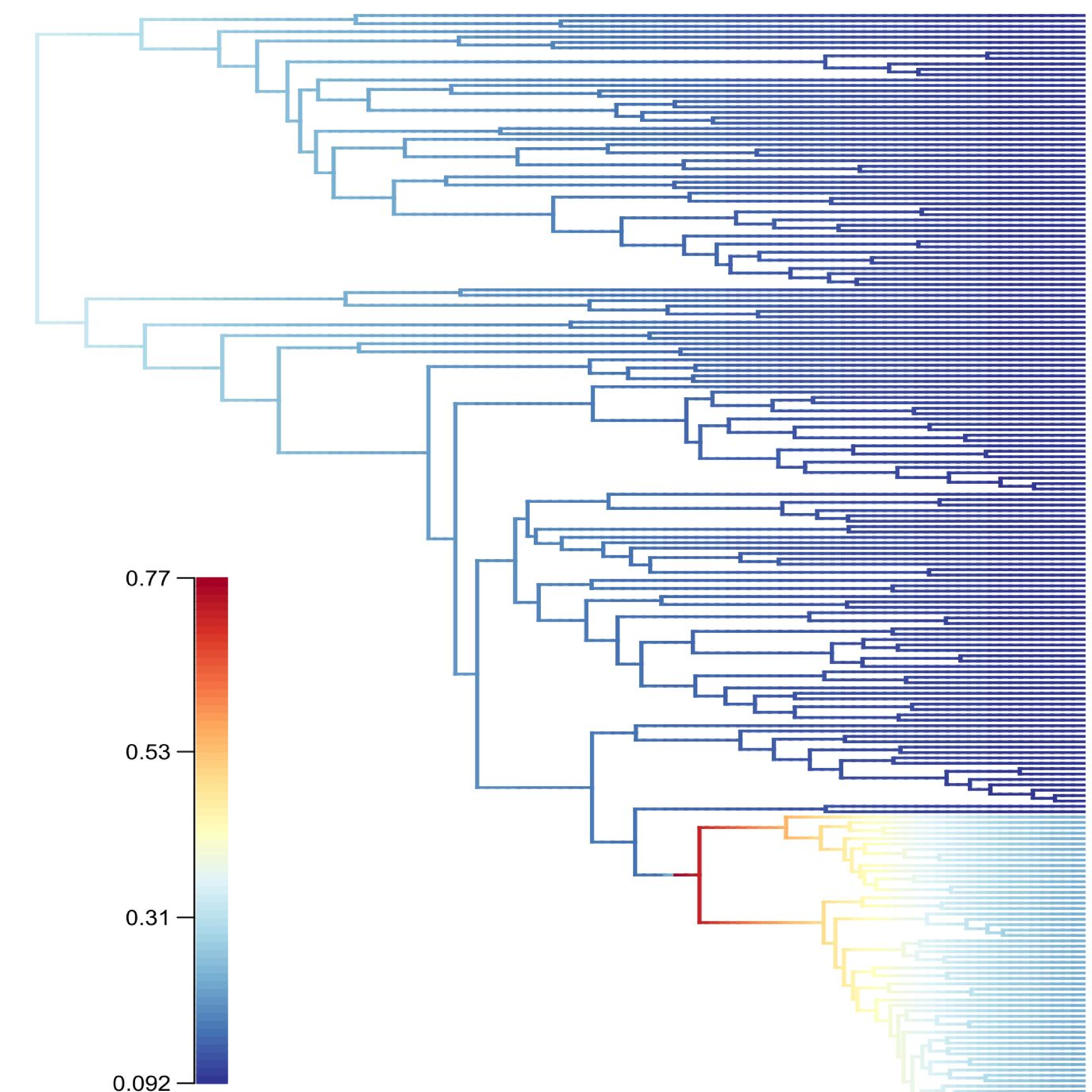


$p=0.8$

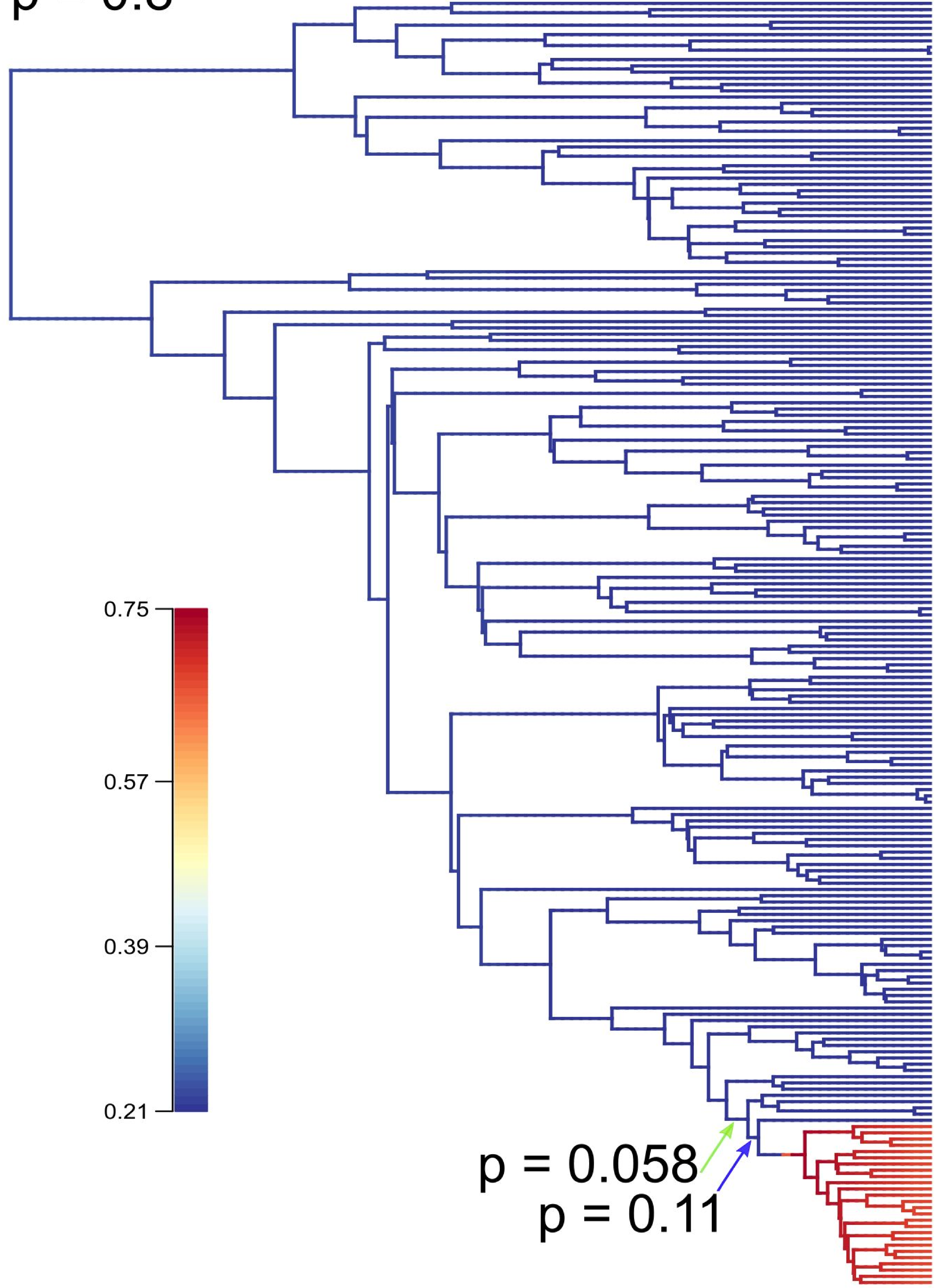

$\begin{array}{llllllll}35 & 30 & 25 & 20 & 15 & 10 & 5 & 0\end{array}$ 
a.

$p=0.54$

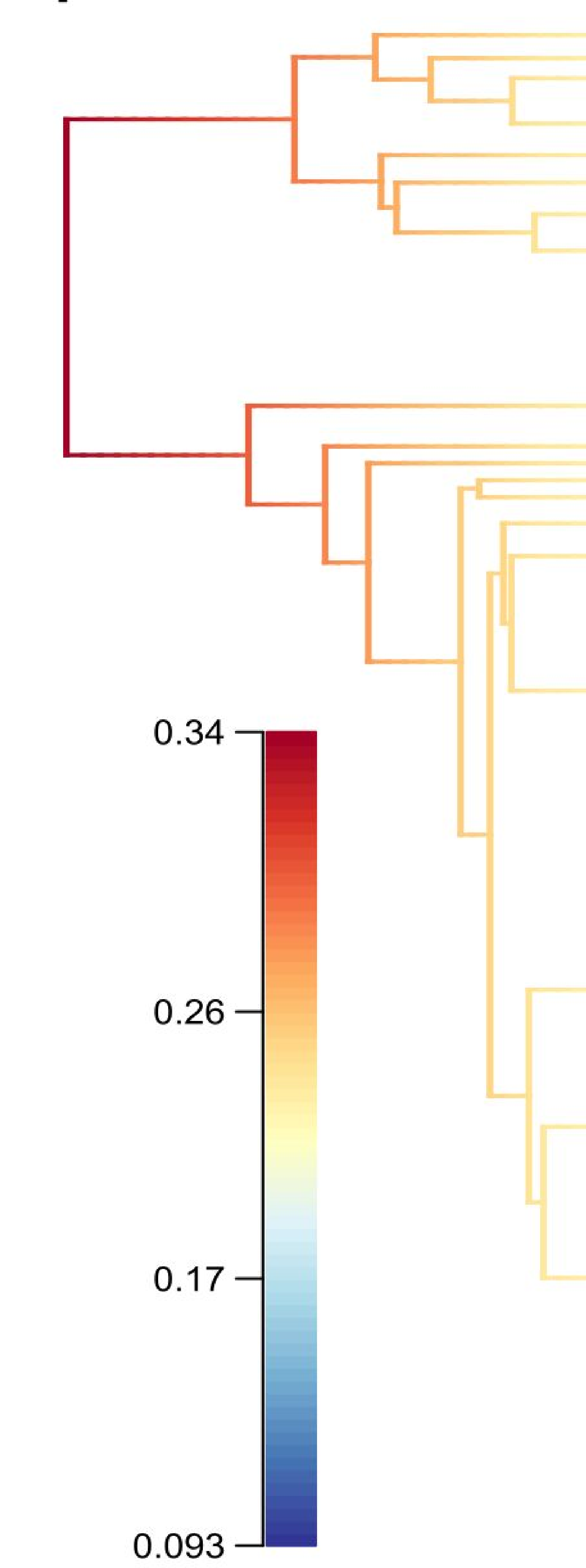

Smoothing $=0.01$

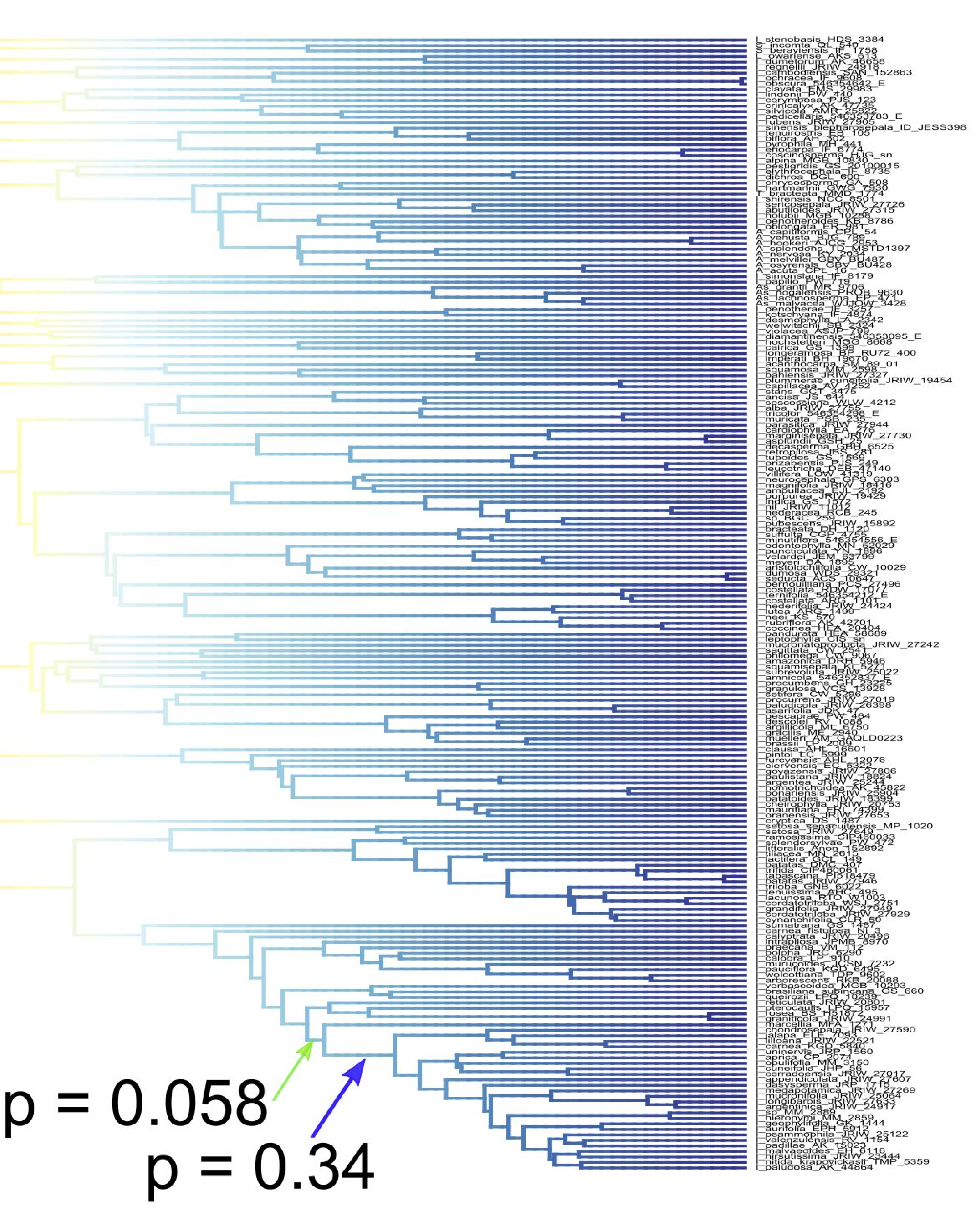

\section{b. $\quad$ Smoothing $=1$}

$p=0.51$

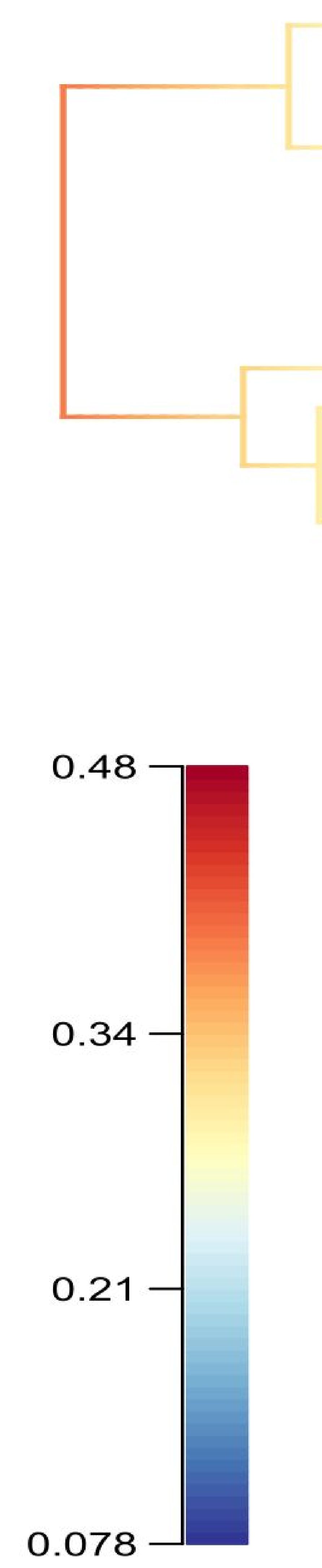

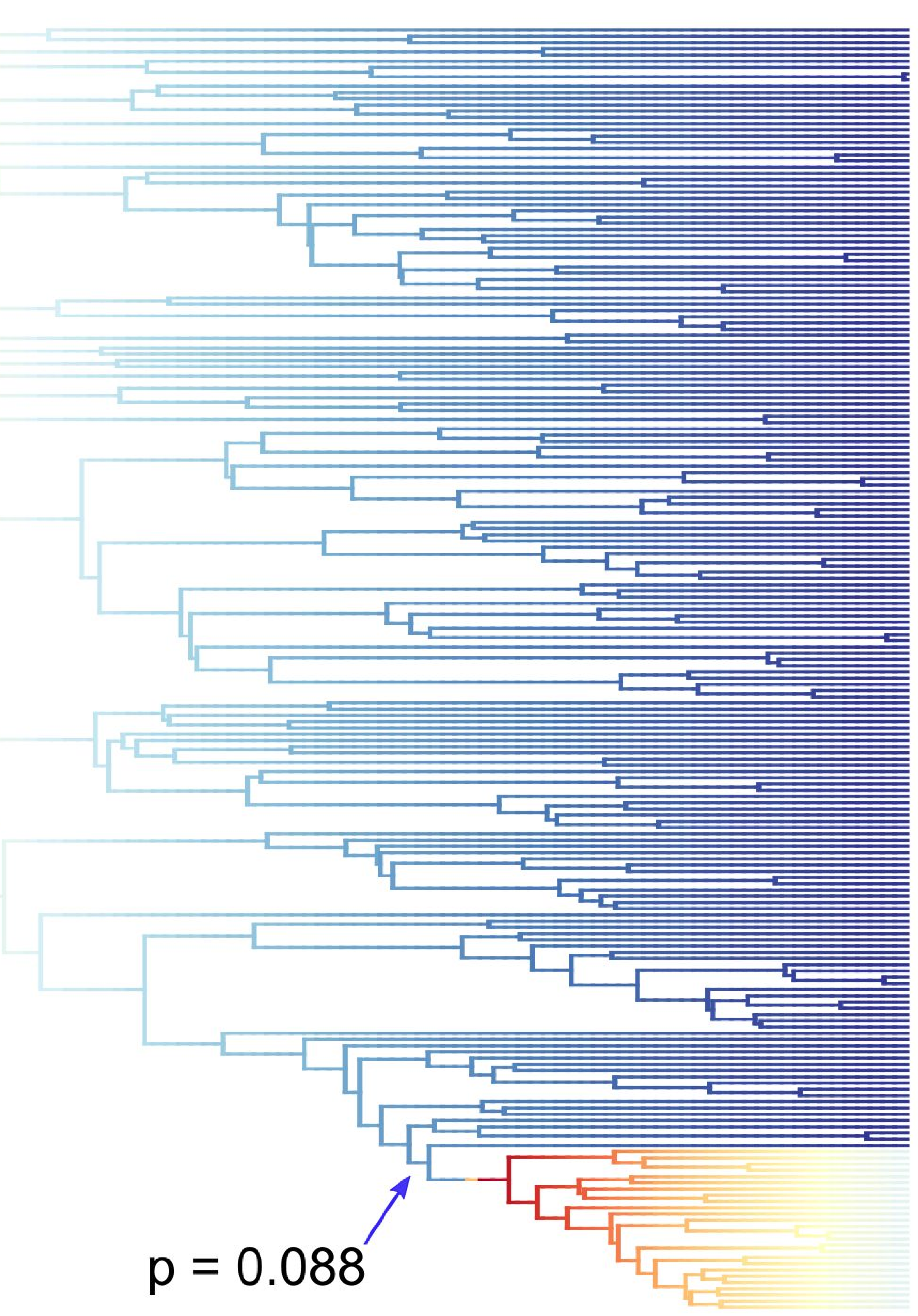

$3 \longdiv { 5 }$

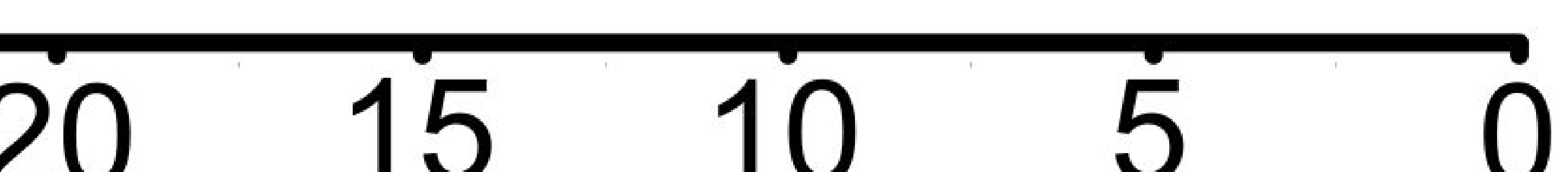

Time (MYA)

\section{c. $\quad$ Smoothing $=100$}

$p=0.81$

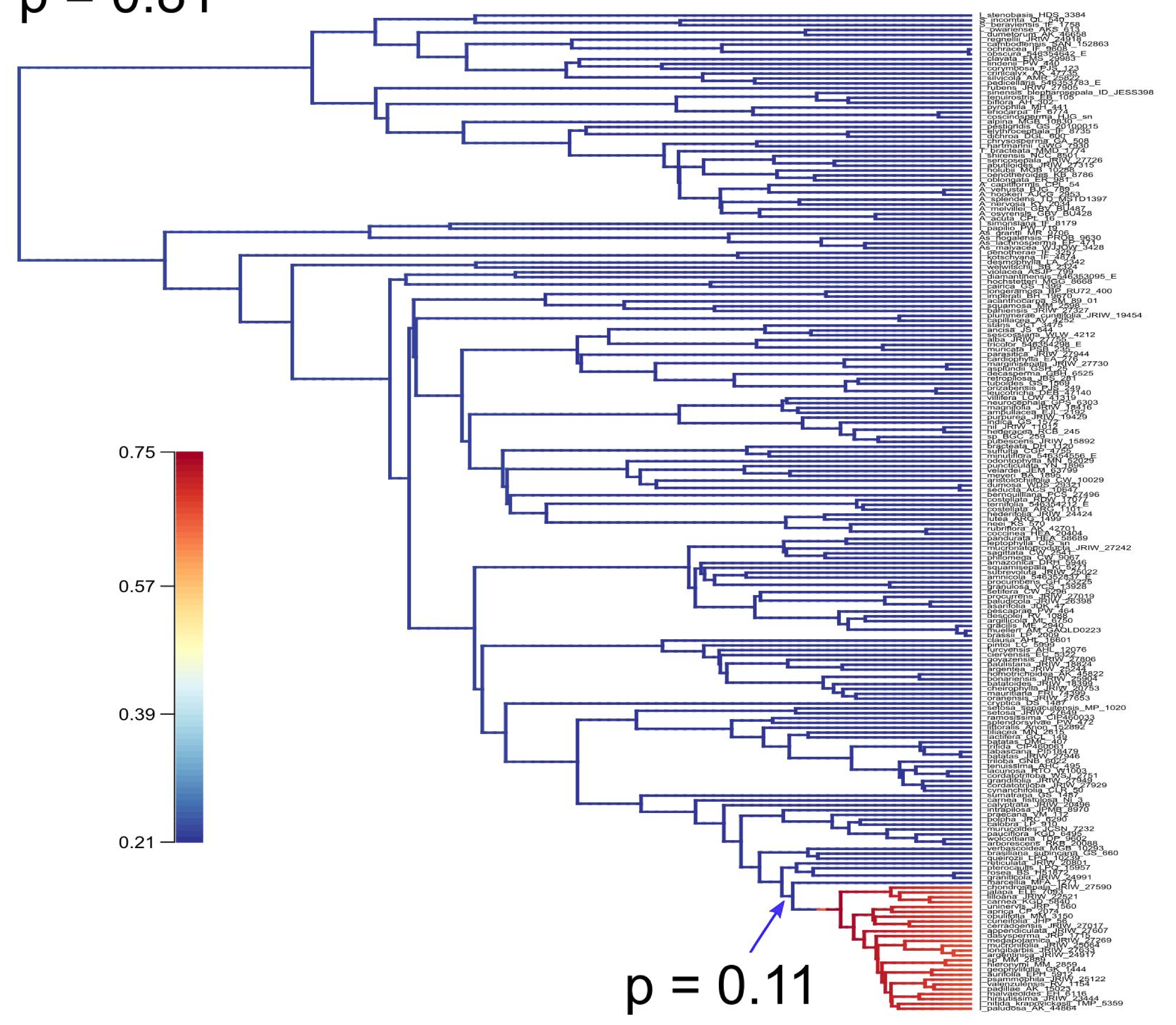

$\begin{array}{llllllll}35 & 30 & 25 & 20 & 15 & 10 & 5 & 0\end{array}$

Time (MYA) 
BIOME

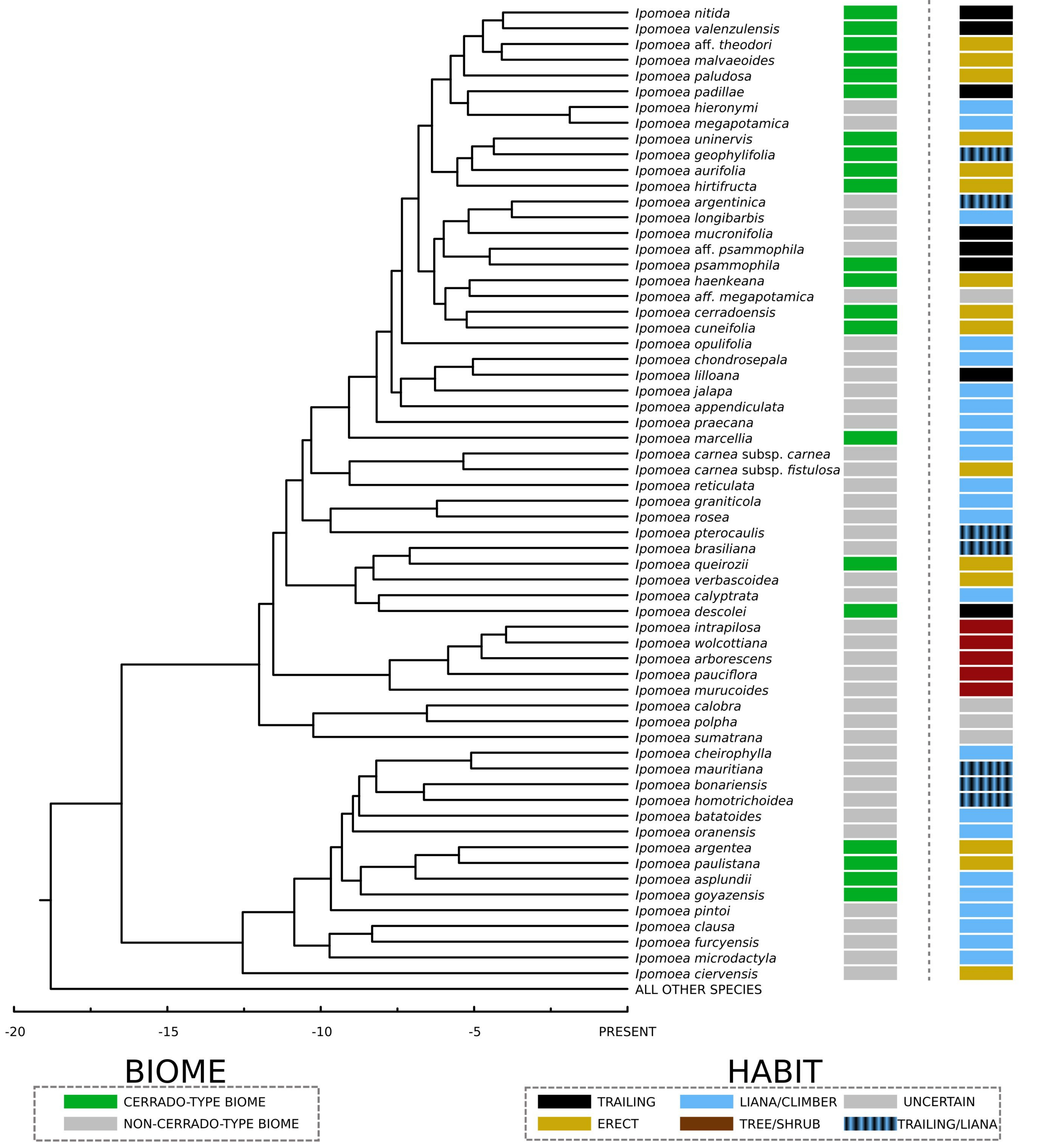

